\title{
Crystallographic patterns in philippine indigenous fabrics
}

Ma. Louise Antonette Delas Penas ${ }^{1}$, Agnes Garciano ${ }^{1}$, Debbie Marie Verzosa ${ }^{2}$

\author{
${ }^{1}$ Mathematics Department, Ateneo De Manila University, Quezon City, Philippines, ${ }^{2}$ Mathematics Department, University of \\ Southern Mindanao, Kabacan, Cotabato, Philippines \\ E-mail: mdelaspenas@ateneo.edu
}

The Philippines is home to various indigenous communities with a rich history of weaving. This paper will demonstrate existence of symmetries in crystallographic patterns found in woven textiles. First, the weaving techniques were classified according to how the designs are created: (1) ikat weaves, where threads are dyed to produce a design, (2) decorative weaves, where the design emerges from the choice of color and patterns of warp over and under weft threads, and (3) supplementary thread weaves, where additional threads are inserted. The main difference between techniques (2) and (3) is that theoretically, if the additional threads in (3) were not inserted, the textile would still "hang together" or be complete.

Our analysis indicates a relationship between the weaving technique and the symmetries produced. As expected from the weaving technique where warp and weft threads are perpendicular, no six-fold symmetry was found. Further, some symmetries were more commonly found in one technique than in others. Common plane crystallographic groups are pm for ikat designs, p1 and pmm for decorative designs, and pmm for supplementary thread designs. While there is evidence of pmg symmetries in all weaving techniques, pg was found only in the supplementary thread design.

The presence of particular symmetric designs are also closely linked to the culture and tradition of these indigenous communities. For example, ethnolinguistic groups from the Cordillera region of Northern Luzon use textile for funerary rituals, and the symmetric motifs present are closely associated to the status of the deceased and reflective of his religious beliefs [1]. Meanwhile, communities in the south produce colorful symmetric designs in the Tausug pisyabit headscarves and kandit sashes reflective of Islamic culture and tradition $[2,3]$.

[1] De las Peñas, M. L. P. \& Salvador-Amores, A. (2016). Phil. Jnl. Sci. 145, 89-103.

[2] Quintos, F. Editor. (2015). Woven Universes, Math, Method, Meaning and Magic in Philippine Indigenous Textiles. Yuchengco Museum.

[3] Respicio, N. (1988). Journey of a Thousand Shuttles. National Commission for Culture and the Arts.

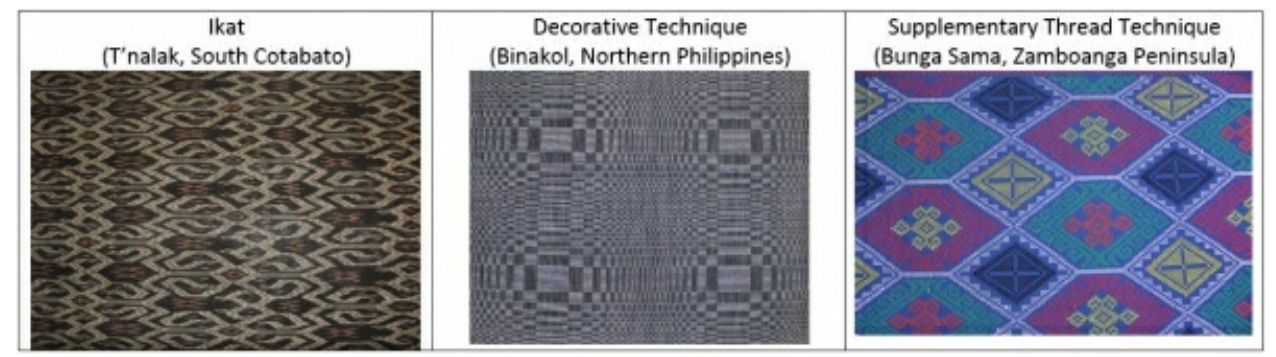

Keywords: crystallographic patterns, symmetries, Philippine indigenous textiles 